\title{
Effect of Lead Monoxide as a Filler on Chemical Stability of Unsaturated Polyester Radiation Shields
}

\author{
V. HARISH ${ }^{1 *}$, T. NIRANJANA PRABHU ${ }^{2}$ and N. NAGAIAH ${ }^{3}$ \\ ${ }^{1}$ Department of Physics, Government First Grade College, Shimoga-577201, India \\ ${ }^{2}$ Department of Chemistry, MS Ramaiah University of Applied Sciences, \\ Bangalore-560058, India \\ ${ }^{3}$ Department of Physics, Bangalore University, Bangalore-560056, India \\ harishvenkatreddy@gmail.com
}

Received 12 October 2014 / Accepted 8 November 2014

\begin{abstract}
Polymer composite radiation shields of Isophthalate based unsaturated polyester resin filled with different concentrations of lead monoxide were investigated for chemical resistance against diffusion of water, sulphuric acid and sodium hydroxide. Pristine polymer was observed to exhibit an excellent stability to all the solvents used. Filled composites were also observed to exhibit good stability against distilled water and $\mathrm{H}_{2} \mathrm{SO}_{4}$ solution. However, lower stability was observed in $\mathrm{NaOH}$ solution due to the reaction between sodium hydroxide and lead monoxide. The effect of filler concentrations on solvent sorption and surface morphology were also discussed.
\end{abstract}

Keywords: Chemical stability, Diffusion coefficient, Polymer composites, Radiation shields

\section{Introduction}

Generally, radiation shielding materials such as lead bricks, high density concrete and metal or metal alloys are heavy and bulky and not preferred under all conditions ${ }^{1-4}$. Radiation resistant high density polymer composites of polymers filled with different metal or metal oxides $^{5-9}$ are widely preferred as flexible radiation shields. Polymer radiation shields are inevitably exposed and interact to different environments during their service life. Unfortunately, most of these interactions do somehow have a harmful effect. Hence, in addition to radiation shielding, it is necessary to test them for other aspects such as thermal, mechanical, chemical and electrical behaviours. In view of this, lead monoxide $(\mathrm{PbO})^{10,11}$ filled Isophthalate unsaturated polyester resin ${ }^{12}$ composites of have been prepared and investigated for above said aspects ${ }^{13-15}$. The results of the chemical stability against diffusion of solvents such as water, an acid and a base have been discussed in this paper.

Diffusion in, permeation through, swelling and relaxation of polymers are the common phenomena involved during these environmental interactions which may cause soluteinduced-plasticization in the composite or swelling induced mechanical stresses leading to environmental stress cracking. Hence, an evaluation of these radiation shields for chemical stability would be essential to predict their performance against different environments. 


\section{Experimental}

Fabrication details of the composites are already reported elsewhere along with the results of radiation shielding ${ }^{13,14}$, thermo-mechanical ${ }^{15}$, thermal $^{16}$ and electrical studies ${ }^{17}$. In this paper, the results of chemical stability have been presented. Rectangular specimens of $25.4 \times 76.2 \times 3 \mathrm{~mm}^{3}$ were oven dried at $100{ }^{\circ} \mathrm{C}$ for $24 \mathrm{~h}$, cooled in desiccators and weighed to the nearest $0.001 \mathrm{~g}$. Water diffusion studies was done according ASTM D 570-99 procedure. ASTM D 543-95R01 procedure was followed for studies in $30 \% \mathrm{H}_{2} \mathrm{SO}_{4}$ and $10 \% \mathrm{NaOH}$. Surface modifications due to solvent diffusion were investigated using metallurgical microscope.

There is no universal model to cover all types of solvent sorption in polymer systems ${ }^{18}$. Generally followed mechanisms are Fickian ${ }^{19}$, case II diffusion ${ }^{20}$ and others ${ }^{21}$. Solvent diffusion in polymers depends on factors like processing techniques, matrix filler characteristics, composition and duration of immersion. Further in polymer systems, amorphous part of the polymer contributes mainly than the crystalline part. Diffusion coefficients depend on the chemical nature of the polymer system and degree of crosslinking $^{22}$. Weight $\%$ gained during sorption and soluble matter $\%$ lost if any during sorption were evaluated to the nearest $0.001 \%$ using the relations,

$$
\begin{aligned}
& \text { Increase i } n \text { weight\% }=\frac{\text { Wet weight }- \text { Reconditioned weight }}{\text { Reconditioned weight }} \times 100 \\
& \text { Soluble matter lost, } \%=\frac{\text { Conditioned weight }- \text { Reconditioned weight }}{\text { Conditioned weight }} \times 100
\end{aligned}
$$

Using the plots of fractional weight gain against $\sqrt{\text { time }}$, diffusion coefficients for different liquids were evaluated using the relation:

$$
\frac{\Delta \mathrm{w}_{\mathrm{t}}}{\Delta \mathrm{w}_{\mathrm{T}}}=\frac{\mathrm{w}_{\mathrm{t}}-\mathrm{w}_{0}}{\mathrm{w}_{\infty}-\mathrm{w}_{0}}=\frac{4}{1} \sqrt{\frac{\mathrm{Dt}}{\pi}}
$$

Where $\mathrm{w}_{\mathrm{t}}, \mathrm{w}_{0}$ and $\mathrm{w}_{\infty}$ are the weights of the samples at immersion time $\mathrm{t}, \mathrm{t}=0$ and at the saturation, $l$ the thickness and $\mathrm{D}$ the diffusion coefficient of respective liquid ${ }^{23}$.

\section{Results and Discussion}

Weight gain in composite samples immersed in distilled water, $30 \% \mathrm{H}_{2} \mathrm{SO}_{4}$ and $10 \% \mathrm{NaOH}$ as a function of $\sqrt{\text { time }}$ have been shown in Figures 1, 2 and 3 respectively. Surface morphology of a composite sample before immersion in solvents has been shown in Figure 4. Modification in surface morphology of composites is depicted in Figures 5 to 8 after immersing in solvents for 120 days. Table 1 , shows the diffusion coefficients of various solvents.

As evident from Figure 1, ILM1 shows less than $0.1 \%$ in $\%$ of weight gain when immersed in water for 24 hours and it ranges up to a maximum of $0.142 \%$ in filled composites. Isophthalic acid based unsaturated polyesters are known for high chemical resistance. Most of the samples attain saturation at around 60 days of immersion. At saturation, ILM1 gains the minimum \% of weight $(0.315 \%)$ while ILM2 gain the maximum $(0.683 \%)$. Among the filled composite samples, ILM 2 with only $5 \%$ of $\mathrm{PbO}$ filler gained the highest $\%$ of weight $(0.683 \%)$ at saturation level and follows a decreasing trend with an increase in filler concentration from ILM2 to ILM7.

These observed results may be attributed to the fact that ILM1 being a thermoset pristine polymer contains tightly bound cross linked polymer layers through which the 
diffusion of water molecules is very much limited. In filled samples at lower filler loadings, the particles are surrounded by a tightly bound polymer covered by a layer of loosely bound chains. As the loading increases, the areas of loosely bound polymer begin to overlap, containing the entire matrix to be influenced by the filler. If filler loading is high, there is little space left for loosely bound polymer and hence the participation of the layers of tightly bound polymer increases ${ }^{23-25}$. Fillers also influence the structure of the polymer matrix due to contribution from filler surfaces to inter phase organization ${ }^{10}$. Therefore ILM2 with lower filler concentration offers more free space inside for water to diffuse through while the ILM7 with higher filler concentration offers the least.

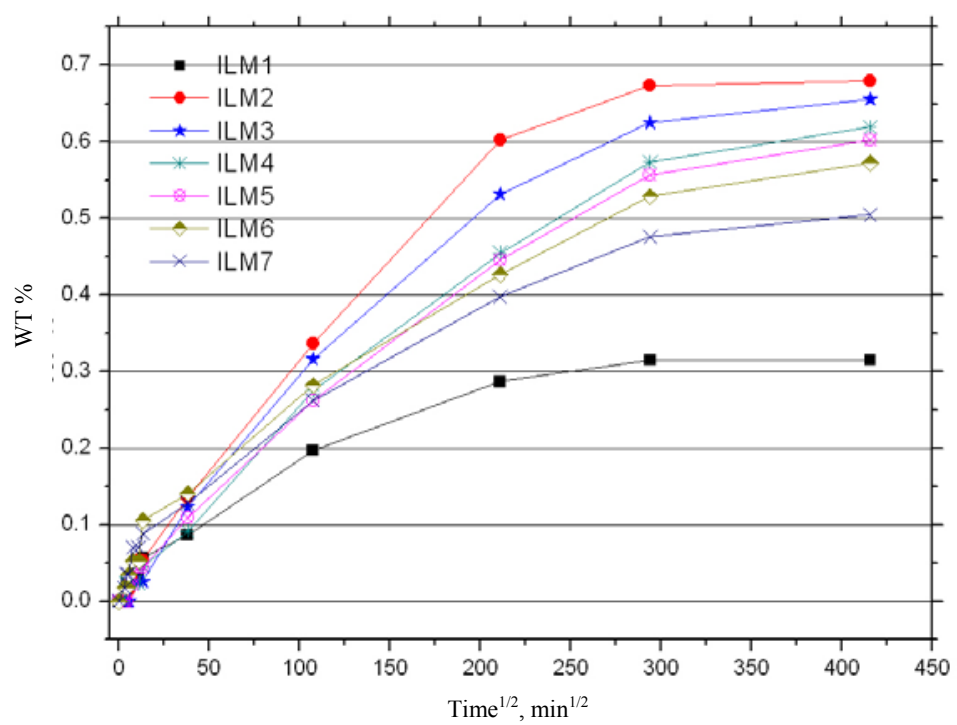

Figure 1. Fractional weight gain in polymer composite samples immersed in distilled water

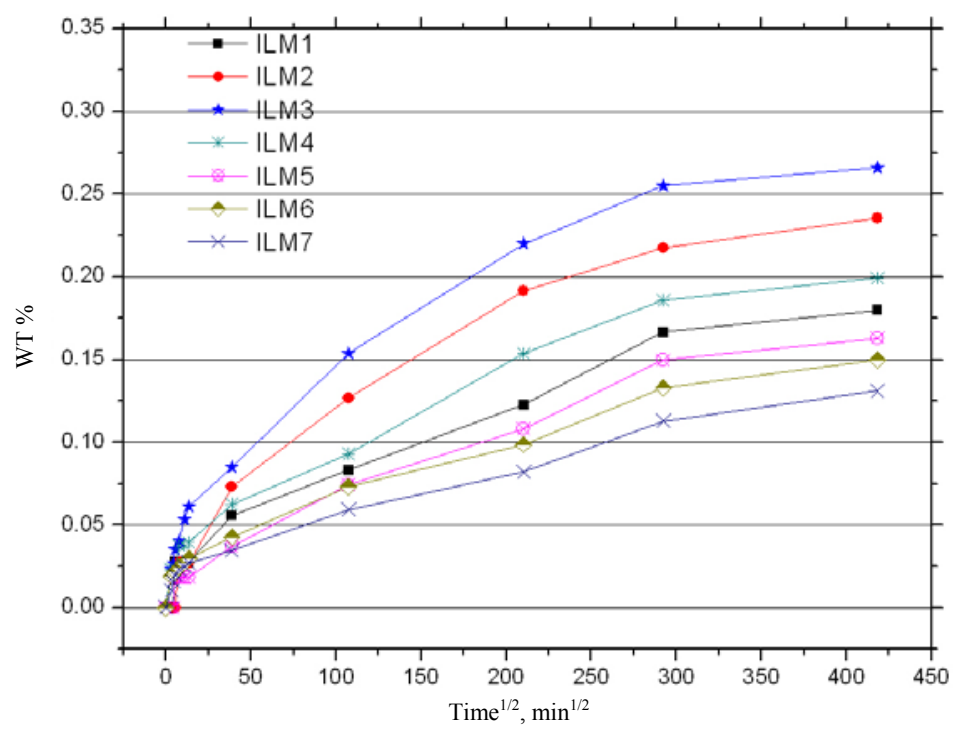

Figure 2. Fractional weight gain in polymer composite samples immersed in $30 \% \mathrm{H}_{2} \mathrm{SO}_{4}$ 


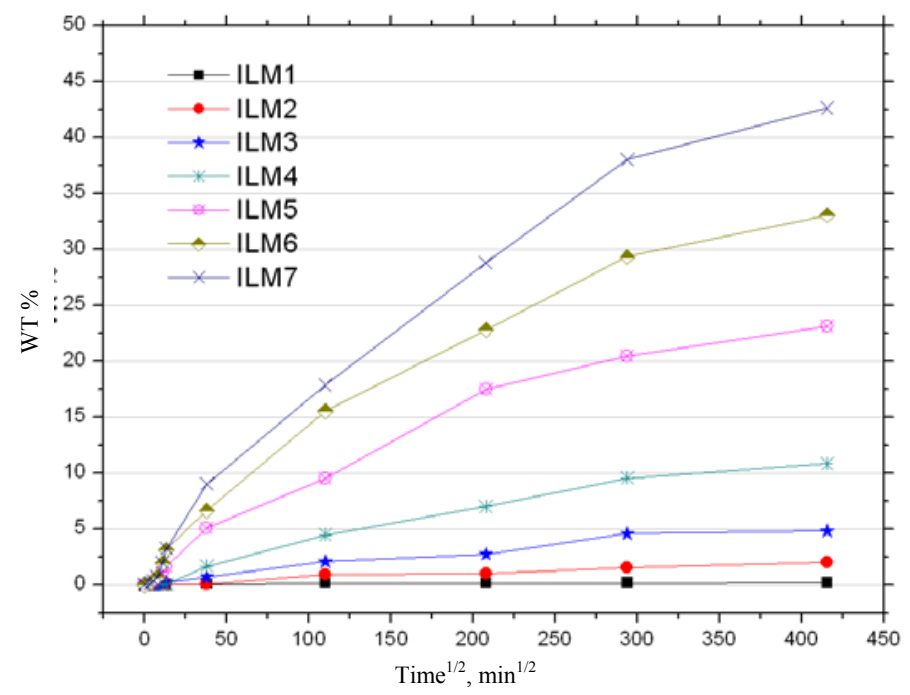

Figure 3. Fractional weight gain in polymer composite samples immersed in $10 \% \mathrm{NaOH}$

Table 1. Diffusion coefficients of distilled water, $\mathrm{H}_{2} \mathrm{SO}_{4}(30 \%)$ and $\mathrm{NaOH}(10 \%)$ solutions in polymer composite samples

\begin{tabular}{ccccc}
\hline \multirow{2}{*}{ Sample } & \multirow{2}{*}{$\begin{array}{c}\text { Wt. \% of } \\
\text { PbO filler }\end{array}$} & \multicolumn{3}{c}{$\mathrm{D}$ (Diffusion coefficients) $\times 10^{-6} \mathrm{~cm}^{2} \mathrm{~s}^{-1}$} \\
\cline { 3 - 5 } & & (Distilled) & $30 \%$ & $\mathrm{NaOH}, 10 \%$ \\
\hline ILM1 & 0 & 6.343 & 6.335 & 6.334 \\
ILM2 & 5 & 6.367 & 6.339 & 6.452 \\
ILM3 & 10 & 6.365 & 6.339 & 6.643 \\
ILM4 & 20 & 6.363 & 6.335 & 7.092 \\
ILM5 & 30 & 6.362 & 6.334 & 8.207 \\
ILM6 & 40 & 6.361 & 6.333 & 9.412 \\
ILM7 & 50 & 6.354 & 6.332 & 10.980 \\
\hline
\end{tabular}

Since $\mathrm{H}_{2} \mathrm{SO}_{4}$ molecules are quite bigger penetrants than water molecules, all the composites were expected to gain less weight $\%$. And also, neither the polymer nor the filler reacts chemically with $\mathrm{H}_{2} \mathrm{SO}_{4}$ acid and hence the diffusion mechanism would be a simple solvent sorption mechanism similar to that of water. At 24 hours of immersion, a weight gain $\%$ was found to be less than $0.05 \%$. At 120 days of immersion, the samples attain saturation in weight gain and ILM3 was observed to gain the highest $(0.262 \%)$ while the ILM7 gains lowest value $(0.135 \%)$. Here $\%$ of weight gain at saturation increases with an increase in filler content only up to ILM3 and thereby it tends to decrease up to ILM7 with a minimum weight $\%$ even than that of ILM1. This trend is quite similar to that of water and may be attributed the same fact that discussed above in case of water diffusion.

Isophthalate based unsaturated polyesters are resistant to even strong alkalies. However, filled composites show poor stability against alkalies' as lead monoxide undergoes reaction with most of the alkalis' and with $\mathrm{NaOH}$ reacts to form sodium plumbite. Hence, ILM1 shows an excellent stability only $0.091 \%$ of weight gain even in 120 days of immersion while the other composites from ILM2 to ILM7 show poor stability as evident from Figure 3. With an increase in filler concentration, the $\%$ of weight gain also increases. 
ILM7 attains a weight gain of $9 \%$ just in 24 hours of immersion and a highest value of $42.631 \%$ in 120 days of immersion. The weight gain in ILM1 may be attributed to a simple sorption mechanism of penetrants into limited free space available in polymer layers. However, in filled composites, diffusion of penetrating molecules as well as loss of $\mathrm{PbO}$ particles due to chemical reaction is involved.

Diffusion coefficients generally depend on chemical nature and cross linking degree of the polymer chains in the composite system. ILM1 being a pristine cross linked polymer shows more stability to diffusion of all solvents. The observed values of diffusion coefficients in filled composites as shown in Table 1, differ as the cross linking degree of the polymer gets affected due to presence of filler particles in between the polymer layers.

Optical micrograph of ILM1 in Figure 4 before immersion in any of the solvents exhibits a rough surface with visible impressions of mould surface. On immersion in solvents for 120 days, surface structure of ILM1 appears clearly with the impressions of mould surface and is as shown in Figures 5, 6 and 7. These observations might be due to loss of loosely bound dust/surface particles and possible swelling of the surface layers due to solvent diffusion. Similar results were also observed for other samples (ILM2-7) immersed for 120 days in water and $\mathrm{H}_{2} \mathrm{SO}_{4}$. However, after immersion of samples from ILM2-7 in $\mathrm{NaOH}$ for 120 days show different surface structure as one shown in Figure 8 for ILM7. Large oval shaped gaps which appear on the surface are due to reaction of surface filler particles and hence a larger \% of weight gains due to diffusion of more solvent into the composite structure.

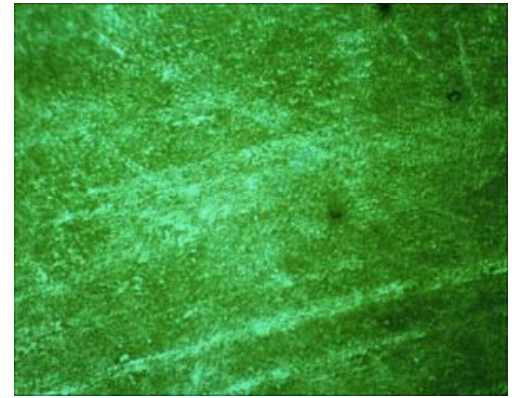

Figure 4. Optical micrograph showing surface structure of ILM1 sample before immersing in the solvents

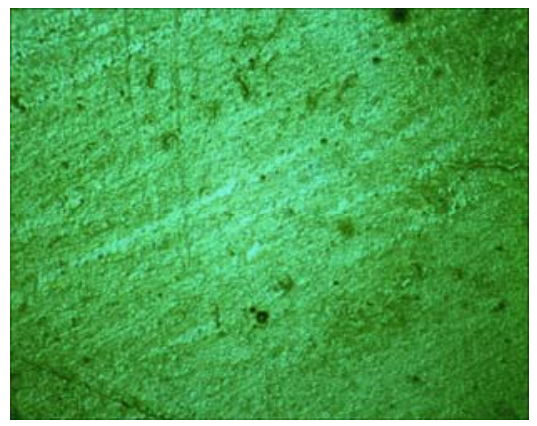

Figure 6. Optical micrograph showing surface structure of ILM1 sample immersed in $30 \% \mathrm{H}_{2} \mathrm{SO}_{4}$ for 120 days.

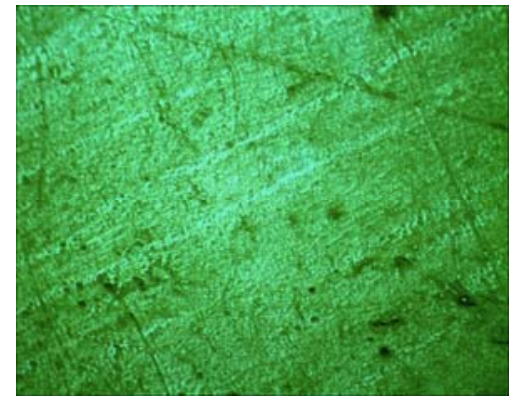

Figure 5. Optical micrograph showing surface structure of ILM1 sample immersed in distilled water for 120 days.

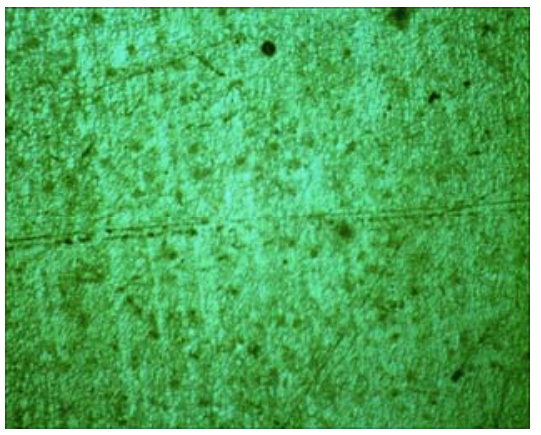

Figure 7. Optical micrograph showing surface structure of ILM1 sample immersed in $10 \% \mathrm{NaOH}$ for 120 days 


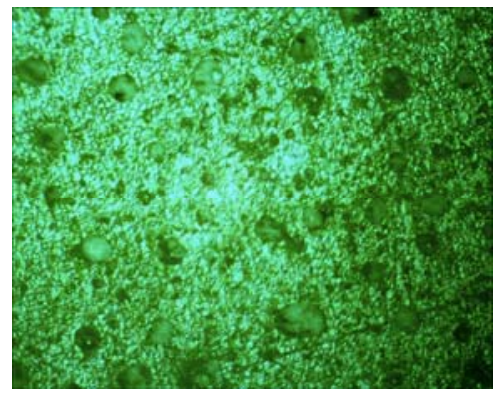

Figure 8. Optical micrograph showing surface structure of ILM7 sample immersed in $10 \%$ $\mathrm{NaOH}$ for 120 days

\section{Conclusion}

The composites were investigated to understand their stability against diffusion of distilled water, $30 \% \mathrm{H}_{2} \mathrm{SO}_{4}$ and $10 \% \mathrm{NaOH}$ solutions. Pristine polymer exhibits an excellent stability to all the solvents used. Filled composites were also exhibit good stability against distilled water and $30 \% \mathrm{H}_{2} \mathrm{SO}_{4}$ solution. However $\mathrm{NaOH}$ solution appears to be more corrosive due to reaction with the filler. An appropriate surface coating on the filled composite samples to minimize the exposure of the filler particles would help to improve their stability against alkalis'. The effect of filler on solvent sorption and surface morphology of the composites were discussed.

\section{References}

1. Holmes-Siedle A and Adams L, Hand Book of Radiation Effects, $2^{\text {nd }}$ Ed., 2002, Oxford Univ. Press, England.

2. Chilton A B, Shultis J K and Faw R E, Principles of Radiation Shielding, 1984, Prentice Hall Inc. New Jersey.

3. Spinks J W T and Wood R J, An Introduction to Radiation Chemistry, 1964, WileyInterscience, New York.

4. Bovey F A, The Effect of Ionizing Radiation on Natural and Synthetic High Polymers, 1958, Wiley-Interscience, New York.

5. Macleod J M, Servant R H and Hector R, Patent No: Eur. Pat. 372758, CA 2003879, JP 02223899, U.S. Pat. 5278219, 1990, Du Pont Canada Inc.

6. Hussain R, Haq Z U and Mohammad D, J Isla Aca Sci., 1997, 10(3), 81-84.

7. Abdul Aziz M M, Badran A S, Abdel-Hakem A A, Healy F M and Moustafa A B, $J$ App Polym Sci., 1991, 42(4), 1073-1080; DOI:10.1002/app.1991.070420420

8. Abdul Aziz M M and Gawaily S E, Polym Degrad Stab., 1997, 55(3), 269-274; DOI:10.1016/S0141-3910(96)00119-X

9. Pavlenko V I, Lipkanskii V M and Yastrebinskii R N, J Eng Phys Thermophys, 2004, 77(1), 11-14; DOI:10.1023/B:JOEP.0000020713.63937.43

10. Harry S, John V Katz and Milewski, Handbook of Fillers for Plastics, 1987, Springer, New York.

11. George W, Handbook of Fillers, 1999, Chem Tech Publishing Company, Toronto, Canada.

12. Hansmann H, Compendium-Composites: ASM hand book on Polyester resins, 2003, ASM International, Ohio, USA.

13. Harish V, Nagaiah N, Niranjana Prabhu T and Varughese K T, J App Polym Sci., 2009, 122, 1503-1508; DOI:10.1002/app.29633 
14. Harish V, Nagaiah N and Harish Kumar H G, Indian J Pure Appl Phys., 2012, 50(11), 847-850.

15. Harish V, Nagaiah N, Niranjana Prabhu T and Varughese K T, J App Poly Sci., 2010, 117(6), 3623-3629; DOI:10.1002/app.32265

16. Harish V and Nagaiah N, AIP conference proceedings, 2011, 1349, 89-90.

17. Harish V and Nagaiah N, AIP conference proceedings, 2011, 1349, 983-984.

18. Xiao G Z and Shanahan M E R, Polym., 1998, 39(14), 3253-3260; DOI:10.1016/S0032-3861(97)10060-X

19. Fick A, Ann Phys., 1855, 94, 59.

20. Thomas N L and Windle A H, Polym., 1982, 23(4), 529-542; DOI:10.1016/00323861(82)90093-3

21. Lekatou A, Faidi S E, Ghidaoui D, Blyon S B and Newman R C, Comp A, 1997, 28(3), 223-236.

22. McEwan I, Pethrick R A and Shaw S J, Polym., 1999, 40(15), 4213-4222; DOI:10.1016/S0032-3861(98)00649-1

23. Cabanelas J C, Prolongo S G, Serrano B, Bravo J and Baselga J, J Mat Process Tech., 2003, 143-144, 311-315; DOI:10.1016/S0924-0136(03)00480-1

24. Tsukuda R, Sumimoto S and Ozawa T, J App Polym Sci., 1996, 59(6), 1043-1046; DOI:10.1002/(SICI)1097-4628(19960207)59:6<1043::AID-APP19>3.0.CO;2-4

25. Tsagaropoulos G and Eisenberg A, Macromol., 1995, 28(18), 6067-6077; DOI:10.1021/ma00122a011 